\title{
Os Usos de Crack em um Contexto de Vulnerabilidade: Representações e Práticas Sociais entre Usuários ${ }^{1}$
}

\author{
Manoel de Lima Acioli Neto ${ }^{2}$ \\ Maria de Fátima de Souza Santos \\ Universidade Federal de Pernambuco
}

\begin{abstract}
RESUMO - O objetivo deste estudo foi compreender os contextos de uso do crack. Para isso, foram entrevistados 14 usuários de crack de diferentes localidades e realizada Análise Temática de Conteúdo das informações obtidas. Os resultados indicam que as representações encontradas nesses contextos situam o crack como droga da destruição, o qual acaba por influenciar no modo de consumir a droga, descrito por episódios de ingestão intensa, com deterioração orgânica e prejuízos para a saúde. Diante dessa discussão, conclui-se que a consideração do contexto enquanto unidade de análise implica em uma possibilidade teórica de abarcar a circularidade do saber, pois retoma a produção de sentidos, sem torná-la estagnada a um grupo ou população.
\end{abstract}

Palavras-chave: representação social, crack (droga), droga (uso), drogas, problemas sociais

\section{Using Crack in a Vulnerability Context: Social Representations and Practices among Users}

\begin{abstract}
The aim of this study was to understand the contexts in which crack is being used. We interviewed 14 crack users in different locations and data were analyzed using category-based content analysis. The results indicate that the representations used in these contexts characterize crack as a drug of destruction, which influences the way of consuming the drug, described by episodes of intense intake, with organic deterioration and damage to health. We concluded that consideration of context as the unit of analysis implies a theoretical possibility of embracing the circularity of knowledge, because it resumes production of meanings, without making it stagnant to a group or population.
\end{abstract}

Keywords: social representation, crack (drug), drug use, drugs, social issues

O objetivo deste estudo foi compreender os contextos de uso do crack, através da análise das representações e práticas sociais relacionadas ao seu consumo e do modo como elas se constroem nas redes interacionais de seus usuários. Considerando-se que essas representações são originadas na interação social desses indivíduos com seus grupos de pertença, a intenção desta pesquisa foi investigar sua elaboração e negociação pelos atores envolvidos nesse processo e suas relações no desenvolvimento das práticas de uso entre usuários.

Essa investigação, portanto, possui um duplo interesse. Por um lado, analisar esse constructo teórico, o contexto, amplamente utilizado, mas pouco discutido enquanto ferramenta conceitual. E, por outro, compreender sua utilização em um fenômeno empírico de larga difusão social: o uso de crack. Assim, a compreensão dos contextos de uso abarca tanto a circularidade desse objeto em meio a distintas redes interacionais, mas também possui um referencial pragmático, que se define pelo entendimento que a significação de um objeto apresenta em seu uso social.

1 Este artigo é um dos estudos derivados da dissertação de mestrado intitulada "Os contextos de uso do crack: Representações e práticas sociais entre usuários", de autoria de Manoel de Lima Acioli Neto e orientação da Prof ${ }^{\mathrm{a}}$.Dr ${ }^{\mathrm{a}}$ Maria de Fátima de Souza Santos

2 Endereço para correspondência: Rua Azeredo Coutinho, 120, B.8, Apt.201, Várzea, Recife, PE, Brasil. CEP: 50741-110. E-mail: mdlacioli@hotmail.com
Essa discussão se torna necessária ao se observar uma tendência de se recorrer aos grupos como referências de análise dos indivíduos, com a justificativa de que, por meio do pertencimento a vários grupos, estes desenvolvem suas condutas, representações e valores. Parte-se da compreensão de que as relações humanas ocorrem sempre em um meio social organizado, como em uma família, grupo, comunidade, que cria representações, técnicas, categorizações, regras e valores essenciais à interação. Contudo, deve-se atentar que a conformação dessas representações também é determinada pelas relações entre os grupos em que se insere, tal como entre outros grupos, de forma que não obtém estabilidade (Berger \& Luckmann, 1996; Bruner, 1997).

Essa característica confere ao saber um caráter circular, no qual o sentido partilhado por dado grupo termina por ser difundido em torno de uma rede, em que a interação direta não necessariamente precisa ocorrer. No entanto, ainda assim, existe uma dinamicidade nesse processo, em que aquilo que foi definido em um dado encontro interacional, ao retornar como saber social, termina por sofrer mudanças no significado, como no "telefone sem fio". No uso, os significados se modificam, tornando-se funcionais às situações em que se difundem. Nessa perspectiva, apesar dessa propensão de se buscar o grupo como uma unidade de sentido social, parece ser na circularidade dos saberes em meio às redes interacionais que o indivíduo se insere, que ocorre a consolidação de um campo epistêmico, o contexto, 
tornando possível se ter acesso à fluidez simbólica dessas construções (Acioli Neto, 2014).

\section{Os Usos Sociais do Crack}

É importante situar a amplitude do fenômeno do crack no âmbito da sociedade brasileira.No mundo, estima-se que aproximadamente 17 milhões de pessoas fizeram uso dessa substância, o equivalente a $0,37 \%$ da população (UNODC, 2015). No Brasil, essa prevalência foi estimada em 400 mil pessoas, 0,8\% da população (Bastos \& Bertoni, 2014). Esses dados indicam as experiências de uso ao menos uma vez na vida, não apenas os casos de dependência da droga.

As concepções predominantes sobre o assunto situam que o usuário da substância tende a perder o controle do consumo, voltando-se à compulsão de usá-la (Donato, Rezende, Ribeiro, \& Silva, 2010), desvinculando-se de suas atividades cotidianas, com prejuízos profissionais e pessoais, além de perda do contato com seus grupos sociais de pertença (Moreira, 2009). Esses efeitos têm sido atribuídos à fissura que a droga pode provocar no usuário, considerada um fator crítico para o desenvolvimento do uso compulsivo e da dependência (Chavez, Sanchez, Ribeiro, \& Nappo, 2011).

Nessa perspectiva, o consumo de crack é um tema de ampla repercussão pública, podendo-se observar atualmente notícias reportadas diariamente sobre essa problemática, salientando aspectos que apontam para uma preocupação pública do uso dessa droga. Essas notícias ressaltam a necessidade de estratégias de enfrentamento através da internação do usuário ou de práticas repressivas ao narcotráfico (Santos, Acioli Neto, \& Sousa, 2012) e apontam para uma "epidemia" desenvolvida em todo o território nacional (Gomes, 2010). O crack é tratado como um problema social grave que necessita de intervenções urgentes (Occhini \&Teixeira, 2006; Scheffer, Pasa, \& Almeida, 2010). Apesar disso, o crack não se situa entre as drogas mais consumidas no Brasil (Chavez et al., 2011; Bastos \& Bertoni, 2014) e nunca se tornou uma droga popular ou amplamente usada em nenhum lugar do mundo (Morgan \& Zimmer, 1997). A ênfase dada ao problema é remetida a um determinismo farmacológico da droga, responsável pela produção de efeitos individuais e sociais diversos, tais como a dependência e o envolvimento com a criminalidade, existindo poucas discussões acerca dos aspectos sociais e culturais envolvidos no fenômeno do consumo.

Ressalta-se que abordar essa dimensão do fenômeno não implica em desconsiderar as implicações farmacológicas da droga. Compreende-se que existem efeitos específicos decorrentes da ingestão do crack e que merecem atenção. O problema ocorre quando outras dimensões são deixadas em segundo plano, tornando a investigação do fenômeno reduzida a características bioquímicas da droga.

Negligencia-se, assim, a experiência dos usuários e as significações e práticas construídas em seus contextos de uso. A investigação desses contextos, assim como da experiência dos efeitos produzidos pelo crack, é relevante para se construirem novas formas de abordagem aos usuários. Compreendendo como esses usuários significam e experienciam os efeitos, assim como as práticas envolvidas nos rituais de consumo, é possível ampliar o conhecimento e o escopo de intervenções sobre esses grupos (Jorge, Quinderé, Yasui,\& Albuquerque, 2013; Wandekoken \& Siqueira, 2013).

A subestimação da eficácia simbólica existente nas significações circulantes a respeito de um objeto social, tal como o crack, remete a um posicionamento que não considera todos os aspectos envolvidos na problemática do uso dessa droga. A significação do que se concebe como droga e os sentidos atribuídos aos seus usos possuem uma variabilidade em função do meio cultural em que se inscrevem (Bucher \& Lucchini, 1992; MacRae, 2000; Zinberg, 1984). Uma mesma substância psicoativa, com propriedades farmacológicas idênticas, possui sentidos que se modificam em relação ao contexto de uso, diante do campo de saberes partilhados em uma rede interacional. Nesse âmbito, as drogas têm um caráter ambíguo que advém de sua natureza simbólica, pois seus sentidos são construídos em contextos que permitem sua significação enquanto objeto social. Esse processo ocorre em uma relação dependente do contexto, pois se vincula às condições sociais, políticas e históricas que configuram contextos determinados (Jovchelovitch, 2008).

Para Morin e Apostolidis (2002), o contexto se define como um sistema de interpretação situado em um espaço de negociação e trocas. Nesse sentido, apresenta-se como uma matriz de interpretação e, portanto, epistêmica. Mas, também, deve ser analisado considerando sua dimensão temporal e situacional, pois se constitui no encontro com o outro, na relação do sujeito com a alteridade.

Desse modo, pode-se afirmar que a definição de uma droga se ancora em contingências e arbitrariedades contextuais, as quais a definirão enquanto um objeto social. Todas as culturas sancionam pelo menos uma substância que causa alterações mentais e, invariavelmente, proíbem com rigor as outras (Burgierman, 2011). É importante observar que, apesar da milenaridade do consumo de drogas, esse tema vem sendo tratado como problema social somente a partir do final do século XIX. Atualmente, o uso de drogas é considerado um dos principais problemas de saúde pública, associando-se a complicações de saúde e, principalmente, sociais, ligados à violência e ao tráfico (Paiva \& Ronzani, 2009).

Em contrapartida, apesar do caráter alarmante em torno da questão das drogas, tem-se identificado a existência de outros padrões de uso de crack, situando-se inclusive a possibilidade de consumo controlado dessa droga (Jackson-Jacobs, 2001; Oliveira \& Nappo, 2008; Waldorf, Reinarman, \& Murphy, 1991; Zinberg, 1984). O consumo controlado se caracteriza como um consumo em longo prazo, não diário e racional, em que o usuário, por meio de estratégias de autocontrole, não permite que a fissura ${ }^{1}$ determine a manutenção do uso (Oliveira \& Nappo, 2008). Deve ser ressaltado que, apesar de existir a possibilidade de um controle no consumo, a realidade encontrada nos principais centros urbanos brasileiros se mostra distante desse quadro: a urgência pelo uso da droga e a intensidade dos efeitos da fissura colocam o risco associado ao consumo da droga como um problema de saúde pública (Chavez et al., 2011). Fica, assim, a pergunta:

1 A fissura é uma vontade irresistível para utilizar uma substância (Seibel \& Toscano Jr., 2000). 
as representações produzidas sobre o crack em diferentes contextos têm relação com o modo de consumir a droga?

Por representação social, define-se a elaboração de um objeto social pela comunidade com o propósito de comunicar e agir (Moscovici, 1963; Wagner, 1998). Contudo, para que esse objeto se diferencie e possa se caracterizar como uma representação social, ele deve estar implicado com os valores partilhados com os outros que se concretizam na pertença a uma dada cultura (Jovchelovitch, 2008).

Dessa forma, o trabalho de representação consiste em amenizar o caráter de estranheza de um dado objeto, introduzi-lo no espaço do comum, do habitual, provocando a aproximação de concepções, de "expressões separadas e díspares que, num certo sentido, se procuram" (Moscovici, 1978, p. 61). Esse trabalho é duplo, pois separa conceitos e percepções frequentemente interligados, tornando o incomum habitual, familiar, além de fazer circular e reunir experiências, vocabulários, conceitos e condutas advindos de diversas origens.

Assim, um objeto social é qualquer entidade material, imaginária ou simbólica que as pessoas nomeiam, atribuindo características e valores e, consequentemente, tornando-se aptas a falar sobre ele, sendo sempre um objeto para um grupo, sociedade ou cultura (Wagner, 1998). As representações são modos específicos de compreender, comunicar e criar a realidade, importantes porque orientam a forma de nomear e definir conjuntamente os diferentes aspectos da realidade cotidiana, interpretando-os e possibilitando tomar decisões e posicionar-se diante destes (Jodelet, 2001). Caracteriza-se por ser uma forma dialógica gerada na interação com o outro pelas inter-relações eu/outro/objeto-mundo (Jovchelovitch, 2008), a partir de outras representações (Moscovici, 1994) e atua enquanto princípio organizador das relações simbólicas (Doise, 2002).

Nesse aspecto, a realidade, o cotidiano, apresenta-se como um conjunto de objetivações, uma rede constituída por uma ordem de objetos que foram designados como tais por meio da interação entre os indivíduos de uma dada cultura. Essas objetivações são significadas pela linguagem, em processos representacionais, os quais se conformam enquanto um repositório objetivo de vastas acumulações de significados e experiências que pode, então, preservar-se no tempo e transmitir-se às gerações seguintes (Berger \& Luckmann, 1996).

Por conseguinte, a realidade da vida cotidiana não é unicamente uma rede de objetivações; ela somente se torna possível por causa delas, em sua trama de sentidos. Dessa forma, constrói campos semânticos ou zonas de significação circunscritas, nas quais por meio de processos interacionais com os outros, o indivíduo pode se constituir (Berger \& Luckmann, 1996).

\section{Método}

Este estudo tem como referencial a abordagem qualitativa. A escolha desse tipo de pesquisa como meio de estudar o assunto ocorre pela possibilidade de análise dos significados e de seus processos de constituição no cotidiano e nas circunstancias de formação, através do diálogo com os atores sociais envolvidos. Parte-se do pressuposto que esse diálogo é emblemático do modo como as representações se constroem no cotidiano, funcionando como caminho para acessar a cultura de certo grupo de pessoas. Para acessar essa experiência, deve-se valorizar a linguagem comum e o uso concreto dos significados como a principal instância de investigação, pois, a partir do uso, a representação constitui convenções e regularidades originadas dialogicamente nas práticas sociais e que se tornam legitimadas enquanto repositório cultural de determinados grupos (Jovchelovitch, 2008).

\section{Local da Pesquisa}

A pesquisa foi desenvolvida em unidades do Programa Atitude (Programa de Atenção Integral aos Usuários de Drogas e seus Familiares) e em cenas de uso de crack localizadas na Região Metropolitana de Recife (RMR), com auxílio de equipes do Consultório na Rua de Olinda. O Programa Atitude tem quatro modalidades de atendimento aos usuários: o Atitude nas Ruas que acolhe os usuários in loco e as outras modalidades que possuem estrutura física nas quais os usuários permanecem por vontade própria. A pesquisa foi desenvolvida na unidade do Cabo de Santo Agostinho. O Programa Atitude é um conjunto de serviços criados a partir do Plano Integrado de Enfrentamento ao Crack e outras Drogas, através da Secretaria de Desenvolvimento Social e Direitos Humanos do Estado de Pernambuco (SEDSDH). Faz parte da rede de serviços do Sistema Único de Assistência Social (SUAS). Seu objetivo é garantir acolhida e proteger usuários com grande exposição à violência, por meio de serviços de abordagem social e acolhimento institucional.

O Consultório na Rua é um programa do Ministério da Saúde, implementado a partir da portaria $\mathrm{n}^{\circ} 122$, de 25 de janeiro de 2011 (Ministério da Saúde, 2011). É uma proposta que procura ampliar o acesso da população de rua e ofertar, de maneira mais oportuna, atenção integral à saúde, por meio das equipes e serviços da atenção básica. É um serviço itinerante que oferta recursos para cuidados básicos de saúde a usuários em situação de alta vulnerabilidade social.

\section{Participantes}

Essa pesquisa contou com a participação de 14 usuários de crack, provenientes de diversas localidades da RMR. A faixa etária desses usuários se situava entre 18 a 35 anos. A maioria possuía um consumo de crack de até três anos, tinha abandonado os estudos no ensino fundamental e apresentava uma renda familiar média de um salário mínimo ${ }^{2}$. O primeiro autor deste artigo participou na atuação dos profissionais do Programa Atitude e do Consultório de Rua durante o período de abril a setembro de 2013. Os usuários foram convidados a participar da pesquisa através da entrada do pesquisador em cenas de uso de crack com as equipes do Consultório de Rua e por meio de profissionais do Programa Atitude, quando se

2 O salário mínimo em vigor no momento da pesquisa (2013) era R\$ 678,00, o equivalente em dólares americanos a U\$ 305,47. 


\section{Considerações Éticas}

encontravam nos serviços. Todos os usuários que atenderam aos critérios de participação foram entrevistados.

O critério de seleção para participar da pesquisa era o indivíduo consumir crack. Procurou-se encontrar usuários de diferentes localidades e com padrões de consumo distintos. Os usuários recrutados em cenas de uso foram levados a um local que oferecia sigilo e privacidade para que temas delicados fossem abordados, tal como aqueles que se encontravam em unidades do Programa Atitude. Contudo, para este grupo foi utilizado como critério de participação apenas os usuários recém chegados/acolhidos no serviço. Essa medida foi tomada com o intuito de minimizar o contato do usuário com a instituição, bem como as possíveis influências pelo lócus de cuidado.

\section{Procedimentos}

Procedimentos de coleta. O período de coleta dos dados teve duração de aproximadamente seis meses (entre abril e setembro de 2013). As entrevistas eram realizadas em turnos e dias da semana variados. Foram realizadas entrevistas semiestruturadas, técnica que possibilita uma cobertura mais profunda sobre determinados assuntos, permitindo abordá-los de forma mais complexa e investigar aspectos delicados (Boni \& Quaresma, 2005). As entrevistas foram realizadas pelo primeiro autor deste artigo, que tem formação de psicólogo. Elas foram gravadas digitalmente e transcritas na íntegra e tiveram duração média de 20 minutos.

Procedimentos de análise. Realizou-se a Análise Temática de Conteúdo das informações obtidas, a qual pode ser definida como um conjunto de técnicas de análise voltadas à descrição dos conteúdos imersos nas comunicações. Essas análises permitem inferir conhecimentos relativos às condições de produção e transmissão desses conhecimentos, através do desmembramento do texto em categorias, seguidas de um reagrupamento por analogias (Bardin, 1977).

As entrevistas foram categorizadas, compondo famílias de significados que contemplavam o discurso dos usuários, situados em unidades hermenêuticas. Nesse sentido, essas categorias eram organizadas por meio do conteúdo discursivo presente nas entrevistas e pela frequência de enunciação. Seguidamente, eram identificadas como compondo determinada família de significados e agregadas em termos de similaridades e relação com a temática discutida.

Esses procedimentos foram realizados com o auxílio do software Atlas.ti. Essa escolha decorreu das possibilidades de sistematização das categorias analíticas ofertadas pelo programa. Além disso, o Atlas.ti possui algumas vantagens em relação às técnicas utilizadas na Análise de Conteúdo. Os recursos de anotações e comentários, a elaboração de relatórios, memorandos, disposição de dados em tabelas e matrizes, etc. É importante destacar que as análises realizadas no software eram manuais, no sentido de não haver procedimentos automatizados de categorização ou interpretação. O Atlas.ti funcionou como um instrumento de análise, facilitando esse processo.
O estudo está conformado às regras do Conselho Nacional de Saúde (CNS), através da Resolução $N^{\circ} 466$ (Ministério da Saúde, 2012), que estabelece as diretrizes e normas regulamentadoras de pesquisas envolvendo seres humanos. Essa pesquisa foi realizada após a aprovação do Comitê de Ética em Pesquisa da Universidade Federal de Pernambuco (CEP-UFPE), CAAE: 13781313.9.0000.5208. Para a garantia do anonimato, foi utilizado um pseudônimo ou outra forma de codificação que não revelasse a identidade dos participantes. Além disso, por tratar de aspectos que poderiam fazer emergir algum sofrimento, caso fosse necessário, existia uma equipe de profissionais capacitados para atender essas demandas dos entrevistados e lhes era garantida a interrupção da participação no momento em que desejassem.

\section{Resultados}

Os discursos analisados indicam a organização das representações do crack entre usuários circunscritas em torno de três agrupamentos principais, nos quais objetos distintos se engendram para a construção do sentido: (a) Prazer/Destruição; (b) Prazer/Dependência; (c) Dependência/ Criminalidade.

\section{O Circuito do Prazer/Destruição}

O uso do crack foi apresentado pelos usuários entrevistados como um modo de prazer único, um momento de completude, que proporciona uma experiência de transcendência, um prazer orgástico, levando o usuário a se inserir em diferentes planos de realidade. Uma vivência ontológica de supressão de si, na qual a experiência prazerosa dos efeitos remete a uma incessante busca por manutenção dessa condição.Entretanto, apesar desse destaque pelo prazer obtido, alguns usuários destacam os efeitos destrutivos do crack. Como descreveram os usuários: "É um negócio tão... Que fica difícil de dizer ... Bate um negócio, uma sensação massa, como se estivesse gozando, entendeu? É uma sensação assim tão... É uma sensação boa" (Carlos ${ }^{3}, 18$ anos).

Uma sensação, assim... como se eu tivesse viajado, como se eu tivesse ido para outro mundo, está entendendo? Senti uma dormência totalmente no corpo. É como se tudo aquilo que eu tinha planejado mudasse de repente. Eu tinha planejado uma coisa. Então, já tomava a sua a mente, a droga e esquecia tudo, sabe? Só pensava no próximo pega, só pensava no próximo pega que eu ia dar, no próximo crack. (Rafael, 22 anos)

O prazer obtido pelo consumo do crack se destacou entre as experiências vividas pelos usuários da droga. A organicidade dos efeitos, como a dormência labial ou o sabor da substância ao ser fumada, foi exaltada nos discursos. Todavia, a experiência de transcender ao momento atual, a supressão temporal, a mudança perceptiva em relação ao ambiente foram os pontos que os usuários demarcaram no enaltecimento à droga. Os relatos indicam a obtenção de um

3 Todos os nomes utilizados nesta pesquisa são fictícios. 
prazer singular, indescritível. Uma experiência delimitadora do modo de encarar a realidade. Esses trechos exemplificam: "Aí o cara fica só olhando para o tempo, parado, o cara fica estatelado. Mas é ligeiro demais, uns 20 segundos ou menos a lombra arreia. Aí só vem a ânsia de fumar mais" (Daniel, 18 anos).

Sentia.... Assim, o lábio adormecer, a boca adormecer, aquele gosto bom né? A sensação foi de.... Sei lá cara. Uma sensação muito, muito boa né? Muito boa mesmo. Vem aquele gosto, aquela lombra, aquele... A sensação não tem explicação não, mas uma sensação muito massa véi. Uma sensação arretada mesmo. E foi quando eu comecei a usar realmente, dar tiro na lata, foi quando as coisas começaram a desandar. (Antônio, 25 anos)

No discurso dos usuários, a caracterização do crack é realizada através de dois agrupamentos principais: o componente prazeroso e o caráter destrutivo da droga, relacionado com diversas práticas. Importante observar como esse discurso se articula com as representações predominantes nos campos midiático e científico.

Essa foi a pior droga que veio, foi para destruir. Porque depois veio crack, veio destruição, morte, muitas mortes. A maioria das mortes, a maioria de presos é tudo por causa de tráfico de pedra. Morte por causa de pedra, tudo por causa disso. (Aline, 21 anos)

Nesse sentido, as representações partilhadas nesses contextos também situavam o crack como droga da destruição, responsável pelo fracasso de planos de vida, desconstrução familiar, carreira profissional, etc. Esse aspecto destruidor se evidenciou também no modo de consumir a droga, que implicava em episódios de ingestão intensa, com deterioração orgânica e prejuízos para a saúde. As práticas de cuidado no consumo se tornavam despercebidas, apesar de presentes, somente sendo atentado o caráter nocivo da experiência. Os usuários relatavam precauções e estratégias de controle no momento do consumo, mas estas se tornavam despercebidas quando abordavam discursivamente a droga, como, por exemplo, os limites de ingestão diária ou medidas que suspendiam o consumo por determinado período. Ao serem questionados sobre o que o crack representa, apenas os aspectos destrutivos eram realçados.

Desse modo, o crack é concebido como a droga que só traz destruição, uma "praga que veio para destruir o mundo" e que controla as ações de quem a consome, levando seu usuário a roubar, matar, etc. As descrições associavam a droga a um processo de desconstrução de projetos de vida, envolvimento com a criminalidade e um fim trágico: "cadeia ou cemitério" (Rafael, 22 anos). Com isso, os efeitos que motivavam ao uso são deixados de lado, sendo evidenciados apenas os prejuízos que a droga pode provocar, apesar do prazer proporcionado pelo consumo estar sempre em evidência, implicitamente. Como afirma Bruno: "Eu acho que o crack é um, que nem muitos dizem: é uma droga que veio para arrasar tudo e todos. Acho que é uma abominação" (Bruno, 35 anos).

Destaca-se no discurso dos usuários uma ancoragem em valores religiosos na construção dessa característica destrutiva, argumentando que as repercussões sociais desse processo se relacionavam a entidades cristãs, como o Satanás ou castigo divino. Essa marca religiosa parece assumir um papel importante na construção social do crack, em especial na culpa que os usuários sentem com os efeitos prazerosos da droga. Essas falas demonstram:

O crack é uma peste. Chegou na Terra para roubar, matar e destruir. Tudo de ruim vêm dela. Morte, ameaças, mortes entre amigos, entre irmãos, família, parentes, destruidor de lar. É devastadora essa droga. Ai eu acordei eu digo "meu irmão não vou ficar nessa não. Não vou deixar Satanás agir na minha vida não". (Carlos, 18 anos)

A influência de elementos da moral cristã pode ser reflexo da formação religiosa dos brasileiros, que termina por se diluir na ordem social como valores cotidianos, desassociados de sua origem. Como afirma Martin-Baró (1987), a cultura cristã predominante termina por projetar valores que perpassam a instituição religiosa, incorporando-se nas normas sociais partilhadas na região. Dados do último Censo do Instituto Brasileiro de Geografia e Estatística (IBGE) revelam que $86,8 \%$ da população brasileira se declara adepta do cristianismo: Católicos - 64,6\% ou Evangélicos - 22,2\% (Ministério do Planejamento, Orçamento e Gestão, 2010).

Além disso, é importante atentar para a quantidade de instituições religiosas desenvolvidas no país para lidar com a problemática do crack. Dados do Censo das Comunidades Terapêuticas no Brasil, financiado pela Secretaria Nacional de Políticas sobre Drogas (Ministério da Justiça, 2013), do Ministério da Justiça, reúnem informações sobre um total de 1.795 comunidades terapêuticas, indicando uma forte influência dessas instituições na problemática referente ao uso de drogas. Nesse âmbito, um dos princípios que regem algumas das comunidades terapêuticas, pautam-se pela imposição da religiosidade, prioritariamente cristã.

A consagração dessas concepções que satanizam as drogas remete a um retorno às teorias animistas, que atribuem propriedades e intencionalidade às substâncias inanimadas. A associação entre drogas e o demônio tem origem em épocas remotas e parece se ancorar em princípios éticos cristãos, como a rejeição ao prazer carnal e a culpa como meio de expiação dos pecados. Essa ética considera que toda ebriedade implica debilidades culpáveis (Escohotado, 1996). A moral cristã abole as possibilidades de prazeres carnais, argumentando que a dor e aflição são modos de aproximação com o divino e atribui à abstinência rigorosa um alto valor ético. Diante dessa matriz valorativa, o prazer se insere no campo da morte e do mal. Nos saberes produzidos embasados nessa ética, são apontados como consequência de práticas hedonistas o esgotamento do organismo, a morte do indivíduo e o dano causado a toda a humanidade, com a constituição de pragas, etc. O indivíduo se torna virtuoso quando desvia do prazer, de sua tentação, não cedendo aos prazeres, uma abertura ao mal (Foucault, 2009).

Nesse sentido, nos dias atuais, a relação da embriaguez (compreendida como qualquer alteração da consciência) com o demônio segue tendo repercussão social. As representações referentes à embriaguez do outro são mordazes e condenatórias. Algumas expressões renascentistas e coloniais de representação da embriaguez podem ser notadas como elementos de um pensamento vivo (Varella, 2013).

Entretanto, além dessa perspectiva cristã, também é importante destacar que essa característica destrutiva possui influências explicitamente observáveis da mídia brasileira, 
sobretudo através do jornalismo policial. Essas notícias ressaltam a violência cometida nos contextos do narcotráfico e a repressão policial, destacando a criminalidade e o alto índice de homicídios nos contextos de uso da droga (Santos et al., 2012).

\section{Uso Controlado x Uso Compulsivo}

Também se evidencia o potencial dependogênico da substância, relacionado com o prazer intenso que o crack promove. A dependência foi fortemente apresentada como um reforçador desse modo de lidar com a droga. Ao afirmar que se encontravam doentes, dependentes do crack, os usuários demonstravam não ter mais preocupações em mediar o consumo, acreditando se tornarem "dominados" pela droga.

De tal modo, os entrevistados relataram que as expectativas sobre o crack partilhadas em seus contextos interacionais associavam essa prática à perda de controle, identificada como um processo de destruição que instaura a impossibilidade de interrupção do consumo. A atribuição de um alto poder de dependência ao crack demarca as ações dos usuários e parece ter papel central no direcionamento a um ciclo de consumo intenso.

É cinco minutos de céu e o resto é de inferno. Você procura...

Tem hora que procura o chão e não acha. Ai o que eu vejo é isso. Se tiver o controle cada um faça o seu, continue se quiser, se não quiser não fume. Mas se não tiver controle é melhor procurar um tratamento, porque se não é cadeia ou cemitério. (Renato, 34 anos)

De acordo com Velho (1987), as representações produzidas a respeito de determinado objeto implicam na constituição de um sistema normativo, uma ordem moral, delimitando fronteiras simbólicas e modos de ser e agir no mundo. Essa consideração a respeito da dependência é relevante ao se observar que as experiências de "dominação" da droga eram passíveis de controles sociais formais ou informais. $\mathrm{O}$ que se passava, contudo, era uma indisponibilidade em se preocupar com o manejo desses controles. A experiência do consumo foi apresentada como sendo sempre mediada por algum tipo de controle, mesmo quando o usuário considerava que a droga havia tomado conta de seu ser. Por exemplo, ao situar seu cotidiano de consumo semanal, relatava ter feito diversas escolhas por conta do trabalho ou por preocupação com a saúde. Entretanto, essas práticas de cuidado não se evidenciam, pois, ao falarem sobre os episódios de uso, apenas o que se ressaltava eram os prejuízos obtidos. Os trechos abaixo descrevem essa relação na descrição de um dos usuários entrevistados.

Às vezes, tinha, eu pegava a onda e dizia "vamos fumar quando eu chegar do trabalho". No meu trabalho, eu nunca fumei não para não me queimar e também não para não perder meu emprego (...) Assim, que via e pá que apareceu uma praga no mundo para destruir, matar, acabar, fazer tudo. Tudo o que é de mal ia fazer. Ai eu "isso é conversa rapaz?". Ai apareceu essa droga para chegar e destruir todo mundo. (Roberto, 29 anos)

Dessa forma, a dependência se apresenta como elemento predominante na representação social do crack, implicando também nas motivações do consumo. Os usuários descreveram que, a partir do momento em que se instaura a dependência pela substância, as ações e decisões se pautam num "controle farmacodeterminado", em que o crack "decide" e leva a realizar atividades que não faziam parte do seu repertório de práticas. Por isso, ao usar e, consequentemente, tornar-se dependente, as atividades de roubo e homicídio são decorrentes dos efeitos da droga. Como destacou Rafael: "Até que eu tentava, lutava para eu parar, mas já estava dependente já, não conseguia mais não. Parar de usar né? Não me via sem... Era muito bom" (Rafael, 22 anos).

Assim sendo, as práticas sociais se desenvolvem em uma relação recíproca com essas representações (Jovchelovitch, 2008). Dessa maneira, constroem-se representações sociais cujos conteúdos não só expressam, mas produzem as relações que se estabelece com os outros em contextos específicos (Jodelet, 1984). Portanto, a entrada do indivíduo na rede de significados, que constitui a cultura, ocorre na interação com os outros e remete à incorporação dos valores partilhados por seus membros, situando o indivíduo enquanto pertencente desse contexto (Bruner, 1997). Parte-se da pertença, não do saber, que depende do contexto e se enraíza em um modo de vida (Jovchelovitch, 2008). Os valores são inerentes ao empenho nesses modos de vida, os quais na sua complexa interação constituem a cultura. Esse empenhamento não é apenas uma preferência, é uma crença, uma ontologia. Devido a sua dependência dos significados, assim como dos procedimentos de interpretação e negociação compartilhados, os valores subjacentes a um modo de vida são incorporados na identidade de cada um e, ao mesmo tempo, situam-no na cultura (Bruner, 1997).

Nessa perspectiva, as representações constituem uma realidade, um ambiente, ainda que simbólico, que formam sistemas de pensar e conhecer o mundo por meio de racionalidades contingentes, tornando o sentido sempre polissêmico. Essa realidade se estabelece pela rotina, pelo hábito (Berger \& Luckmann, 1996) e as reações que sucedem aos acontecimentos cotidianos, as respostas aos estímulos, relacionam-se a determinada definição, comum aos indivíduos que pertencem a uma rede interacional, um dado contexto (Moscovici, 2003).

A realidade social, consequentemente, determina-se por aquilo que é aceito socialmente enquanto realidade (Lewin, 1948), conformando-se na trama de representações que são impostas aos indivíduos e que são o produto de uma sequência completa de elaborações e mudanças que ocorrem no decurso do tempo, em sucessivas gerações. Assim, elas se apoiam em valores variáveis, segundo os contextos de onde tiram suas significações, e em saberes anteriores, os quais são relembrados por uma situação social específica (Jodelet, 2001).

Por isso, apesar da existência de um efeito advindo das propriedades químicas da droga, a orientação da experiência parece se relacionar com as expectativas pelos efeitos "conhecidos". A eficácia simbólica das representações possui um poder predominante em relação à própria experiência orgânica, farmacológica. Além disso, o modo como o consumo é simbolizado, a função que essa prática desempenha, o sentido que adquire na vida de cada usuário tem um papel determinante. Não somente a química, mas a 
história de vida e o lugar simbólico do crack também estão envolvidos.

\section{As Relações entre Dependência e Criminalidade}

Conforme Becker (2008/1963), o uso de uma droga atua a partir das concepções que um indivíduo possui a seu respeito, assim como dos usos a que se destina. Essa concepção se desenvolve ao longo de sua experiência com a droga, enquanto objeto social. Assim sendo, perante essa compreensão da dependência, os usuários consideravam que o envolvimento com a criminalidade era uma consequência do consumo do crack. A dependência orientava suas ações à prática de crimes. Porém, a associação com pessoas que cometiam furtos ou assaltos, por exemplo, decorria de uma norma vigente naqueles contextos, anterior ao consumo. O crime, nessa rede interacional, já era uma atividade legitimada. Ressalta-se que, tal recurso possui alguns desvios, pois apesar de os usuários estabelecerem discursivamente uma relação causalística entre o crack e as práticas criminosas, demonstram que não estão inseridos nessa realidade. Para alguns, o único meio legitimo para obtenção do crack é através do trabalho.

É importante destacar que a despeito de se encontrar diversos usuários que eventualmente se tornam ladrões ou assassinos, precisa-se atentar para o processo de mediação de normas, práticas e circunstâncias na construção dos efeitos de uma droga (Morgan \& Zimmer, 1997). Como afirmado anteriormente, os efeitos advindos do uso de uma substância têm ligação direta com os contextos sociais de uso, não decorrendo apenas desuas propriedades farmacológicas, mas também das práticas locais desenvolvidas por grupos (Becker, 1963/2008).

Por isso, a relação do consumo de crack com a criminalidade, em ações como o furto ou roubos parece se associar diretamente com as representações partilhadas sobre o assunto, demonstrando uma inter-relação entre as práticas desenvolvidas e as representações. O processo deve ser compreendido de forma dialética, pois a construção dessas representações também pode ter ocorrido em contextos em que o crime era uma atividade legitimada entre seus participantes.

Porque o usuário de crack ele rouba que só a bexiga né? Rouba, mata, muita gente mata para roubar. Como passa na TV, o cara rouba, o cara mata. A sociedade já olha com um jeito diferente para o cara. Não são todos, mas fica com pena da pessoa. Mas tem muita gente que chega já olha com outro olho, de outro jeito o cara, discriminando o cara. (Daniel, 18 anos)

Segundo os usuários, esse processo de inserção em atividades de roubo, muitas vezes, tem início nas interações com outros indivíduos que já as praticavam. O consumo de crack também se torna um modo de inserção social, diante de algumas redes interacionais. Desse modo, a influência social e a legitimidade dessas práticas como modos de aquisição da droga levavam o indivíduo a cometer tais crimes. É a fissura da droga, de acordo com os usuários, que motiva a ação do roubo, um processo quase orgânico. Marcos e Antônio explicaram: "Porque eu andava com gente que pensava em roubar, matar, sequestrar. Eu andava com gente assim. Ai desse jeito eu queria mudar e nunca ia mudar" (Marcos, 19 anos); "Fumava numa boa e quando acabava ficava sem saber onde buscar dinheiro, aí batia aquela nóia na cabeça de roubar. Ai eu pegava e ia roubar mesmo, ia assaltar pegar celular, carteira" (Antônio, 25 anos).

Desse modo, apesar dos usuários afirmarem que suas ações não são determinadas por essas normas, as representações hegemônicas em seus contextos de uso remetem a essas atividades como verdades sobre o crack. $\mathrm{Ou}$ seja, mesmo vivenciando outras experiências com a droga, acreditam que seu uso remete ao âmbito do prazer destrutivo, da impossibilidade de ação voluntária, na encarnação de uma figura de repulsa. As normas sociais vigentes na informalidade desses campos convocam os usuários a se tornarem dependentes, criminosos e incapazes de construir planos de vida.

Quando eu comecei a me envolver mais dentro das drogas ai eu me ligava nos caras lá roubando. Quando eu comecei, eu não comecei a roubar, não. Trabalhava, tinha o dinheiro que meu pai me dava e depois quando a minha família descobriu que eu estava usando droga parou de me dar, quando eu estava usando crack né? Aí eu comecei a traficar, comecei a roubar pra usar. Todo dia, todo dia de manhãzinha saía de casa e era o dia todinho, roubando, usando, vendendo, usando. (Daniel, 18 anos)

Essas normas se configuram em meio a um contingente de práticas sociais legitimadas em torno do uso do crack, as quais são todas criminalizadas, tal como o furto, roubo, tráfico. O campo de orientação desse objeto situa que essas são as práticas decorrentes ou relacionadas ao crack. Mesmo quando o trabalho se encontra extremamente evidenciado, como valor referencial para as práticas do usuário, ainda assim é a criminalidade que prevalece como norma de ação. O usuário é o ladrão, o criminoso, ao ponto de se tornar destacado o consumo do crack como não sendo o marcador do "usuário". O que conforma o "noiado" é sua inserção em atividades criminosas, seu desrespeito ao outro, à sociedade.

Nesse sentido, deve-se atentar que essas representações se constituem diante de um contexto delimitado pelas relações estabelecidas entre os indivíduos que o compõem através dos processos interacionais. Essa delimitação constrói e possibilita a circulação de saberes específicos, contingentes àquela rede, mas também possui função ontogenética, ao possibilitar a emergência desse campo. Por isso, são representações que apontam para um dado contexto de significação. Um contexto demarcado pela pobreza e pela criminalidade como atividade típica dos indivíduos que o constituem.

\section{Considerações Finais}

Ao longo do estudo foi apresentado que o compartilhamento do sentido, de representações, articula-se na constituição de um contexto, ao mesmo tempo que esse contexto delimita e norteia ou normatiza as relações e produções simbólicas entre seus participantes. Diante disso, observou-se que os saberes construídos pelos usuários em dada rede interacional desempenham papel normativo, prescrevendo ações desenvolvidas em torno certo/errado, normal/anormal, 
aceito/excluído e adquirindo, assim, eficácia simbólica por meio de sistemas de significação e práticas partilhados pelos indivíduos.

Essas representações possuem função determinante na construção das práticas e na orientação das experiências de uso vivenciadas. Experiências que se manifestam por meio das normatizações oriundas dos contextos de significação (mas que também produzem normatizações) $\mathrm{e}$, consequentemente, das redes interacionais nas quais os indivíduos se inserem. Assim, nesse cotidiano, em suas realidades, emerge uma ética própria, contingente aos seus contextos de produção.

Por isso, considera-se que o foco no contexto implica em uma possibilidade teórica de abarcar a circularidade do saber, considerando que retoma uma unidade de produção de sentidos, sem torná-la estagnada a um grupo ou população. A ênfase dessa produção ocorre em sua fluidez interacional, em uma matriz de sentidos decorrentes dos saberes que se constroem e se difundem. Dessa forma, aponta-se o contexto como um campo ético-epistêmico-ontológico. Ético porque prescreve um conjunto de hábitos e práticas que conformam estilos de vida válidos, diante da realidade culturalmente delimitada. Epistêmico na perspectiva de dotar sentido à realidade, com saberes produzidos no encontro com o outro, na interação e no cotidiano. E ontológico devido à possibilidade de fazer emergir tipos de existência, modos de ser contingentes. Assim, é um fenômeno estabelecido em meio às redes de interação de referência dos indivíduos e que delimita as possibilidades de ser, agir e conhecer. Como afirmado anteriormente, trata-se da interação conformada na complexidade das relações que o indivíduo se vincula. São redes de saber, campos de produção de subjetividade, espaços de emergência ontológica e ética.

\section{Referências}

Acioli Neto, M. L. (2014). Os contextos de uso do crack: representações e práticas sociais entre usuários (Dissertação de Mestrado). Centro de Filosofia e Ciências Humanas, Universidade Federal de Pernambuco, Recife.

Bardin, L. (1977). Análise de conteúdo. Lisboa: Edições 70.

Bastos, F. I., \& Bertoni, N. (2014). Pesquisa nacional sobre o uso de crack: Quem são os usuários de crack elou similares do Brasil? Quantos são nas capitais brasileiras? Rio de Janeiro, RJ: ICIT/ FIOCRUZ.

Becker, H. S. (2008). Outsiders: Estudos de sociologia do desvio. Rio de Janeiro: Jorge Zahar.

Berger, P. L., \& Luckmann, T. L. (1996). A construção social da realidade. Petrópolis: Vozes.

Boni, V. \& Quaresma, S. J. (2005). Aprendendo a entrevistar: como fazer entrevistas em Ciências Sociais. Revista Eletrônica dos Pós-Graduandos em Sociologia Política da UFSC, 2(3),68-80.

Bruner, J. (1997). Atos de significação. Porto Alegre: Artes Médicas.

Bucher, R., \& Lucchini, R. (1992). À Procura de uma abordagem interdisciplinar da toxicomania. Em R. Bucher (Org.), R. Drogas e Drogadição no Brasil (pp. 160-181). Porto Alegre: Artes Médicas.

Burgierman, D. R. (2011). O fim da Guerra: A maconha e a criação de um novo sistema para lidar com as drogas. São Paulo: Leya.
Chavez, T. V., Sanchez, Z. M., Ribeiro, L. A., \& Nappo, S (2011). Fissura por crack: Comportamentos e estratégias de controle de usuários e ex-usuários. Revista de Saúde Pública, 45(6), 1168-1175.

Doise, W. (2002). Da Psicologia Social à Psicologia Societal. Psicologia: Teoria e Pesquisa, 18(1), 27-35.

Donato, E. M., Rezende, E. P., Ribeiro, M., \& Silva, C. J. (2010). Farmacologia e neurobiologia do consumo de crack. Em M. Ribeiro \&R. Laranjeira (Orgs.), O tratamento do usuário de crack (pp. 76-89). São Paulo: Casa Leitura Médica.

Escohotado, A. (1996). Historia elemental de las drogas. Barcelona: Anagrama.

Foucault, M. (2009). História da sexualidade 2: O uso dos prazeres. Rio de Janeiro: Edições Graal.

Gomes, J. C. (2010). Anjos caídos: Sarjeta do crime e do crack. Florianópolis: Bookess Editora.

Jackson-Jacobs, C. (2001). Refining Rock: Practical and Social Features of Self-Control among a Group of College-Student Crack Users. Contemporary Drug Problems, 28, 597-624.

Jodelet, D. (2001). Representações Sociais: um domínio em expansão. Em D. Jodelet (Org.), Representações Sociais (pp. 17-44). Rio de Janeiro: EdUERJ.

Jodelet, D. (1984). Réflexions sur le traitement de la notion de représentation sociale en psychologie social. CommunicationInformation, 4(213), $15-41$.

Jorge, M. S., Quinderé, P. H., Yasui, S., \& Albuquerque, R. A. (2013). Ritual de consumo do crack: aspectos socioantropológicos e repercussões para a saúde dos usuários. Ciência e Saúde Coletiva, 18(10), 2909-2918.

Jovchelovitch, S. (2008).Os contextos do saber. Petrópolis: Editora Vozes.

Lewin, K. (1948). Resolving social conflicts. Nova Iorque: Harper \& Row.

Macrae, E. (2000). Antropologia: Aspectos Sociais, Culturais e Ritualísticos.Em S. D. Seibel \& A. Toscano Jr. (Orgs.), Dependência de drogas (pp. 25-34).São Paulo: Atheneu.

Martín-Baró, I. (1987). El latino indolente: carácter ideológico del fatalismo latinoamericano. Em M. Montero (Org.), Psicologia Política Latinoamericana (pp. 135-162). Caracas, Venezuela: Panapo.

Ministério da Justiça. Secretaria Nacional de Políticas sobre Drogas (SENAD). (2013). Censo das Comunidades Terapêuticas no Brasil. Brasília, DF: Senad. Retirado de http://www.mapa-ct. ufrgs.br/

Ministério da Saúde, Conselho Nacional de Saúde. (2013, junho). Resolução $N^{\circ} 466$ de 12 de dezembro de 2012. Dispõe sobre as diretrizes e normas regulamentadoras de pesquisas envolvendo seres humanos. Diário Oficial da União [da] República Federativa do Brasil.

Ministério do Planejamento, Orçamento e Gestão. (2010). Instituto Brasileiro de Geografia e Estatística. Contagem Populacional. Censo 2010. Rio de Janeiro, RJ: IBGE. Retirado de http:// censo2010.ibge.gov.br/

Ministério da Saúde. (2011). Portaria $n^{\circ} 122$. Define as diretrizes de organização e funcionamento das Equipes de Consultório na Rua. Brasília: Author. 
Moreira, E. C. (2009). Uso do crack nas metrópoles modernas: Observações preliminares sobre o fenômeno em Salvador, Bahia. Em A. N. Filho, E. Macrae, L. A. Tavares, \& M. Rêgo (Orgs.), Toxicomanias: incidências clínicas e socioantropológicas (pp. 113-121). Salvador: EDUFBA, CETAD.

Morgan, J. P., \& Zimmer, L. (1997). The social pharmacology of smokeable cocaine: Not all it's cracked up to be. Em C. Reinarman \& H. G. Levine (Orgs.), Crack in America:Demon drugs and social justice (pp.1-17). Berkeley: University of California Press.

Morin, M., \& Apostolidis, T. (2002). Contexte social et santé. Em G. Fischer (Org.),Traité de psychologie de la santé (pp. 463489).Paris: Dunod.

Moscovici, S. (2003). Representações Sociais: Investigações em Psicologia Social. Petrópolis: Vozes.

Moscovici, S. (1994). A melhor maneira de se provar o pudim ainda é comendo-o. Em C. Sá (presidência), $2^{a}$ Conferência Internacional sobre Representações Sociais, Rio de Janeiro.

Moscovici, S. (1978). A representação social da psicanálise. Rio de Janeiro: Zahar.

Moscovici, S. (1963). Attitudes and Opinions. Annual Review of Psychology, 14, 231-260.

Occhini, M. F.,\& Teixeira, M. G. (2006). Atendimento a pacientes dependentes de drogas: atuação conjunta do psicólogo e do psiquiatra. Estudos de Psicologia, 11, 229-236.

Oliveira, L. R., \& Nappo, A. S. (2008). Caracterização da cultura de crack na cidade de São Paulo: padrão de uso controlado. Revista de Saúde Pública, 42(4), 664-671.

Paiva, F. S., \& Ronzani, T. M. (2009). Estilos parentais e consumo de drogas entre adolescentes: Revisão sistemática. Psicologia em Estudo, 14(1), 177-183.
Resolução no 109. (2009, 11 de novembro). Aprova a Tipificação Nacional de Serviços Socioassistenciais. Diário Oficial da União, Brasília, DF.

Santos, M. F. S., Acioli Neto, M.L.,\& Sousa, Y. S. O. (2012). Representações sociais do crack na imprensa pernambucana. Estudos de Psicologia (Campinas), 29(3), 379-386.

Scheffer, M., Pasa, G. G., \& Almeida, R. R. (2010). Dependência de Álcool, Cocaína e Crack e Transtornos Psiquiátricos. Psicologia: Teoria e Pesquisa, 26(3), 533-541.

Seibel, S.D.,\& Toscano Jr, A. (2000). Conceitos básicos e classificação geral das substâncias psicoativas. Em S. D. Seibel \& A. Toscano Jr. (Orgs.), Dependência de drogas (pp. 25-34). São Paulo: Atheneu.

United Nations Office on Drugs and Crime. (2015). World Drug Report 2015. Vienna: United Nations Publications.

Varella, A. C. (2013). A embriaguez na conquista da América: Medicina, idolatria e vício no México e Peru, séculos XVI e XVII. São Paulo: Alameda.

Velho, G. (1981). Individualismo e cultura. Rio de Janeiro: Jorge Zahar Editor.

Wagner, W. (1998). Social Representations and Beyond: Brute Facts, Symbolic Coping and Domesticated Worlds. Culture and Psychology, 4, 297-329.

Waldorf, D., Reinarman, C.,\& Murphy, S. (1991). Cocaine changes:The experience of using and quitting. Philadelphia: Temple University Press.

Wandekoken, K., \& Siqueira, M. (2013). Aplicação do modelo de Neuman e diagnósticos de nanda ao cuidado do usuário de crack. Ciencia y Enfermería, 19(2), 125-139.

Zinberg, N. (1984). Drug, set and setting. New Haven: Yale University Press. 